have inventories of vaccine intended for public clinics. Some of the vaccines have been purchased with state funds and some with federal grants from the CDC. $\mathrm{CDC}$ had set aside the appropriate amount of excise tax from vaccine grants, assuming the tax would be reinstated soon. It has been estimated that a state's tax liability could reach $\$ 3$ million at a time when states are cash-strapped for basic services. Dr. Walter Orenstein, Director of the CDC's National Immunization Program, said the CDC was not consulted and that "this may create one more impediment to raising immunization rates."

FROM: American Medical News. September 13, 1993.

\section{States Get Funding for TB Treatment and Follow-up}

Congress has given the states an option for new federal funds for TB treatment and followup. Included in the federal budget bill passed in August 1993 is a five-year, \$205-million outlay for Medicaid coverage of TB drugs and related services. The proposal, sponsored by U.S. Representative Henry Waxman (D-Calif), gained widespread support in both houses. In addition to prescription drugs for treatment and preventive therapy, the additional funds will cover services such as chest radiographs, home nurse visits, and outpatient followup. Coverage would begin January 1, 1994.

State health officials say the biggest advantage is coverage of directly observed therapy and case management services. Earlier this year, the CDC recommended that all TB patients be considered for DOT and receive an initial four-drug treatment regime.

Traditionally, the states have been responsible for budgeting TB care with their own funds. This bill would create a process to ensure supplemental funds. This does not mean that states can use federal funds to free state money for other things; rather, this is a supplemental funding based on need. The Health Care Financing Administration, which administers the federal portion of Medicaid, would develop a formula to distribute the funds where they are needed the most. New York will be high on the list: In 1992, it led the nation in TB incidence, with 25 cases per 100,000 .

Another bill introduced in the Senate (S 1249) by Edward Kennedy (D-Mass) would allocate \$200 million to the CDC for fiscal 1994 for prevention, control, and elimination programs; \$26 million to the CDC for research, demonstration projects, and education and training; \$46 million to the National Institute of Allergy and Infectious Disease for research; \$5 million to the Food and Drug Administration for research, including the development of medication implant devices; and
\$25 million through the CDC to renovate hospitals and clinics that treat TB patients.

FROM: American Medical News. September 13, 1993; and AID S Policy and Law. August 20, 1993.

\section{Hantavirus-Associated Illness Identified in North Dakota}

On August 27, 1993, a previously healthy 14-yearold North Dakota boy died suddenly after a brief, unexplained febrile respiratory illness. Subsequent examination at CDC of specimens from this patient demonstrated the presence of serum immunoglobulin $\mathrm{M}$ antibody to the hantavirus antigens, a positive polymerase chain reaction assay for hantavirus genetic sequences in multiple tissue, and a positive immunohistochemical stain for hantavirus antigen in lung tissue, confirming the diagnosis of acute hantavirus infection. The patient had no history of recent travel outside the west north central region. An ongoing investigation of this illness is being conducted.

The recognition of this case in North Dakota, in addition to previously confirmed cases that have occurred outside the four-comers region of the Southwest, reinforces the need for clinicians throughout the United States to maintain a high index of suspicion for this condition and to inform health authorities of suspected cases. As of September 15, 36 cases have been confirmed in the United States.

\section{Malaria Diagnosed in 130 + U.S. Military Personnel Returning from Somalia}

Malaria has been diagnosed in 48 U.S. military personnel who had onset of illness while in Somalia between December 1992 and April 1993, and in 83 additional military personnel following their return from Somalia (through June 1993). Of 53 investigated cases, Plasmodium vivax was detected in 41 of the cases, Plasmodium falciparum in nine, a mixed vivax and falciparum infection in two, and Plasmodium ovale infection in one. This substantial number of cases has reinforced concerns regarding malaria prophylaxis, and it underscores the need for prompt recognition and treatment of malaria in military personnel returning from Somalia and in other persons who have traveled to infested areas.

Mefloquine was used for malaria prophylaxis by 38 persons and doxycycline by 15 persons. Because of the reportedly low frequency of vivax and ovale malaria in Somalia, terminal prophylaxis with primaquine to prevent relapses of vivax or ovale malaria following departure was not recommended for Army personnel. Although terminal prophylaxis had been 